\title{
Technology at the dining table
}

\author{
Charles Spence ${ }^{*}$ and Betina Piqueras-Fiszman
}

\begin{abstract}
In this article, we highlight some of the various ways in which digital technologies may increasingly come to influence, and possibly even transform, our fine dining experiences (not to mention our everyday interactions with food and drink) in the years to come. We distinguish between several uses of technology in this regard: For example, to enhance the taste/flavour of food; to provide entertainment and/or to deliver more memorable experiences around food and drink; not to mention helping those who want to eat more healthily. We outline the different routes by which digital technology may arrive at the table (and in some cases already has): on the one hand, technology may be provided by the restaurants or bars for their diners'/patrons' benefit; on the other, it may be brought to the table by the diners themselves (most likely via their own handheld portable electronic devices). While many of the former technological innovations will no doubt first make their appearance at the tables of cutting edge high-end restaurants, the most successful of them will likely be appearing at the home dining table within a couple of years. Like it or not, then, digital technologies will constitute an increasingly common feature of the dining table of the future.
\end{abstract}

Keywords: Technology, Dining, Food \& drink, Multisensory experience, Molecular gastronomy

\section{Review}

Introduction

The primary question to be addressed in this review is how a variety of emerging (not to mention, rapidlydeveloping) digital technologies [1] will increasingly come to be integrated into, and hence change (hopefully for the better), our dining experiences in the years to come. Initially, it seems probable that some of us (the lucky few) will initially experience this merging of, or interaction between, technology and cuisine while dining out at one of the increasing popular restaurants serving molecular (or modernist) cuisine (for example, [2,3]). Sometime thereafter, and this transition will likely take a couple of years, we will increasingly start to find some of the same technologies while sitting around the table with friends and family, who themselves may either be physically present, or else perhaps might just be 'virtually' there (for example, see the fascinating, albeit futuristic, work on 'the telematic dinner party'; $[4,5]$ ). While the tremendous growth of (not to mention surge of interest in) modernist cooking in recent years has relied, at least in part, on the development and utilization of new technologies in the kitchen [6,7], we

\footnotetext{
* Correspondence: charles.spence@psy.ox.ac.uk

Crossmodal Research Laboratory, Department of Experimental Psychology, Oxford University, South Parks Road, Oxford OX1 3UD, United Kingdom
}

( United Kingdom believe that there is tremendous scope here to revolutionize our eating and drinking experiences/behaviours through the intelligent marriage of food and drink with the latest in digital technology.

Now, while one sees a number of such developments emerging from restaurants (and often reads about them in press releases and news stories), it is worth bearing in mind that various technologies have already made their way, more or less unannounced, into many of our everyday restaurants. One sees, for example, the increasing use of technology at the dining table: Think only of the waiters whose orders are nowadays transmitted electronically to the kitchen direct from the tableside (rather than relying on the traditional paper-and-pencil notepad or, worse still, the waiter's memory). However, over-andabove restaurants starting to provide digital technology at the table, it is important to note that many diners are themselves increasingly using their own portable electronic technologies while dining. This can be anything from the diners distractedly fiddling with their BlackBerry during the meal through to the increasingly common trend for diners to document their meal at a fancy restaurant by using the self-same devices to photograph the dishes and then blog/tweet about the experience (even at the very same time as they are eating; $[8,9])^{\text {a }}$

Ciomed Central

(c) 2013 Spence and Piqueras-Fiszman; licensee BioMed Central Ltd. This is an Open Access article distributed under the terms of the Creative Commons Attribution License (http://creativecommons.org/licenses/by/2.0), which permits unrestricted use, distribution, and reproduction in any medium, provided the original work is properly cited. 


\section{Technology on the dining table}

While digital technologies may initially assist the waiter to transfer the diner's order straight to the kitchen, it may not be all that long before there is no longer any need for a waiter in the first place. At least not if Inamo, a recently-opened restaurant [10] is anything to go by. The diners in this futuristic London venue place their orders from an illustrated food and drinks menu that is projected directly onto their table (see also [11], and see [12] for a low-tech version of a similar idea related to using the table-top as a source of information). ${ }^{\mathrm{b}}$

From the diner's side, there certainly ought to be options here to use the increasingly ubiquitous handheld technologies at meal-times (think BlackBerries, tablet computers, and so on; $[1,13])$. It can't be long now before diners start to use their portable electronic devices in order to help them navigate through menus and make better-informed food choices [14]. Such technologies ('the SatNav of food choice and menu selection' if you will) might, for example, be used to help the diner spot any bargains on the wine list, or else perhaps to translate menu items while dining abroad, or else to provide helpful information about any of the obscure ingredients that might appear on their menu. Indeed, we might all need such technological assistance, once more and more restaurants dispense with the need for the waiter to visit your table prior to your ordering! In fact, given all of the information that is now at our disposal over the web, one might ask whether it is not somewhat strange that we mostly still leave the decision about what to order from the menu until we actually arrive at the restaurant itself (a time that most of us would surely rather spend chatting with our dining companions or else savouring an aperitif)?

Talking of technology on the dinner table, a number of experimental kitchens, and even a few restaurants, have recently started to experiment with the possibilities associated with projecting images directly onto the food sitting on the dinner table. For example, at El Celler de can Roca in Spain (see [15]), a variety of projections over the food dishes give the impression of bringing the food very much to life. One projection, in particular, makes the dish look like the surface of an egg that dramatically cracks open, to reveal the food within/underneath.

Another kind of entertainment that is now being offered by restaurants and bars through technology is achieved by incorporating new socializing interactive technologies in their counters, table-tops, or even in the walls themselves (for example, see i-Bar or i-Wall; [16]) that produces sounds or lights up as the diner touches them.

\section{Transforming the experience of eating/food by means of technology at the table}

'The sound of the sea seafood' dish (which has been the signature dish served on the tasting menu at Heston
Blumenthal's, The Fat Duck restaurant in Bray [17] for a number of years now) provides an excellent example with which to highlight the way in which digital technologies can be used to deliver a genuinely different kind of multisensory dining experience $[18,19]$. The waiter arrives at the table holding a plate of seafood that looks very much like the seashore in one hand, and, in the other, a seashell out of which dangles a pair of iPod earphones (see Figure 1). The waiter instructs the diner to insert the earphones before starting to eat, whereupon they hear the sound of the sea: the waves crashing gently on the beach together with a few seagulls flying around overhead.

In the case of 'The sound of the sea' dish, the technology (nothing more than a miniature iPod) completely transforms the dining experience, both by enhancing the taste/ flavour of the food itself (see [19], for evidence on this score $)^{\mathrm{c}}$, and by getting the diner to pay more attention to the gustatory (and auditory) experience itself. Indeed, some diners have been known to find the multisensory experience so powerful that they have broken into tears when confronted by this dish (for example, see [20]). When the first author dined at Blumenthal's flagship restaurant recently, it was striking how nearby tables of erstwhile talkative diners were suddenly silenced once they had put their earphones in. It is undoubtedly the case that diners are likely to take more notice of the flavours/textures at play in a dish if their attention is squarely focused on it, rather than, say, on the latest gossip being conveyed by one's dining companions [21]. In part, the idea here is that diners should come away from 'The sound of the sea' dish thinking rather more carefully about the multisensory dining experience, and the role that sound plays in the experience of what it is that one is eating and drinking. As Blumenthal himself puts it: 'Sound is one of the ingredients that the chef has at his/her disposal'.

Much of the current excitement, then, around the merging of digital technology with food at the dining table lies precisely in the fact that it holds the potential to radically change our experience of dining, and to do so in a manner that many diners genuinely seem to appreciate. This will likely happen first at the tables of the Michelin-starred molecular gastronomy restaurants (such as The Fat Duck in Bray). ${ }^{\mathrm{d}}$ However, we predict that within a couple of years, a number of the more successful of these technological innovations will likely start appearing at the home dining table.

\section{Augmented reality (AR) food: a case of technology for technology's sake?}

In recent years, the proceedings of many an international conference on human-computer interaction (HCI; such as Siggraph, Ubiquitous Computing, and so on) have increasingly started to include contributions 


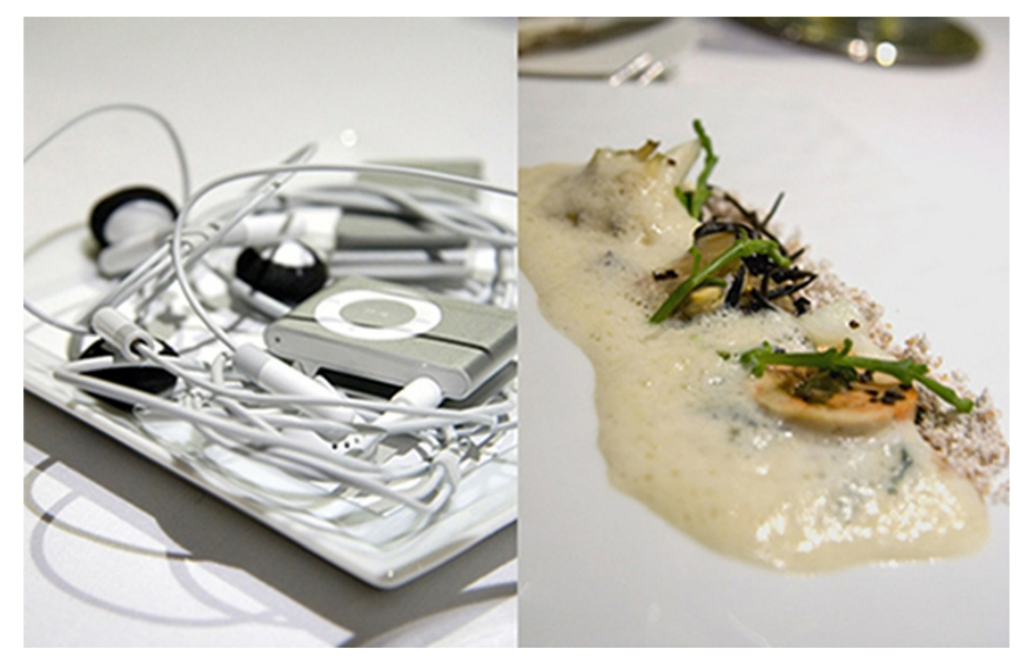

Figure 1 'The sound of the sea' seafood dish (the signature dish served on the tasting menu at Heston Blumenthal's, The Fat Duck restaurant) provides an excellent example with which to highlight the way in which digital technologies can enhance the multisensory dining experience. The experience of eating seafood can be enhanced by listening to the waves crashing gently in the beach, with the seagulls flying overhead.

from those researchers working on the development of a variety of food-related augmented reality (AR) applications. Computer-mediated human-food interactions are certainly attracting growing research interest from the HCI community $[14,22,23]$.

A few years ago now, Hashimoto and colleagues $[24,25]$, also working out of Japan, developed a strawlike user interface. This AR device could be used to recreate the sounds and feeling (or vibrations) that one would normally expect to be associated with sucking a particular liquidized (or mashed) food up through a straw. To operate, the user simply places the straw-like device over a mat showing the food that one would like to try and then sucks on the straw. The audio-tactile experience delivered by this technology is surprisingly realistic/immersive; this despite the fact that no actual food passes the user's lips. Such technologies often enable their users to experience food in a completely different way: they can also help to bring out the playful elements in our interaction with food [26]. ${ }^{\mathrm{e}}$

For example, some researchers are currently working on technologies that will enable their users to listen to a variety of different sounds whenever they happen to close their jaw while eating (Figure 2) [27]. This technology, known as the 'Mouth Jockey', incorporates a light sensor to detect the user's jaw movements and then plays back a specific pre-recorded sound. So, for example, the sound of someone screaming could theoretically be presented while the user of the Mouth Jockey was munching on a mouthful of Jelly Babies, say. Alternatively, however, a microphone taped to the user's jawbone can also be used to amplify the user's own selfproduced biting sounds instead (as in the preceding example). As yet, though, it is hard to see any practical application for this technology other than simply its entertainment value. Another related example is the EverCrisp App., developed by Kayac Inc., Japan (but, as yet, sadly not licensed by Apple) (Figure 3). The idea here was to develop an App. for mobile devices that would enhance the crunch of noisy (for example, dry) food products simply by changing the sound that people heard as they bit into a particular food (see [21,28], for the background). ${ }^{\mathrm{f}}$

Many other research groups (predominantly, it would seem, those working out of Asia) are currently developing a veritable assortment of AR and virtual reality (VR) applications that will soon enable their users to change the apparent colour, texture, and even the size of the food that they are eating (Figure 4) [29-31]. While such technological innovations undoubtedly help to highlight just what is possible through the marriage of technology with food, it would not seem too unfair to suggest that many of those working in the $\mathrm{HCI} /$ Ubiquitous Computing arena focus a little too much of their energy on showcasing what the technology can deliver without necessarily spending enough of their time thinking about the practicalities associated with implementing the technology, no matter whether it be in the context of the high-end restaurant or home-dining setting.

\section{Using QR codes to change our interaction with food}

Another potentially interesting technology when it comes to the experience of food results from embedding QR (quick response) tags in/on food itself [18,32,33], for example, QR Code Cookies (Qkies; [34-36]). Once a food item (for example, a cookie) incorporates such a tag, a person can then use his/her mobile device to scan 


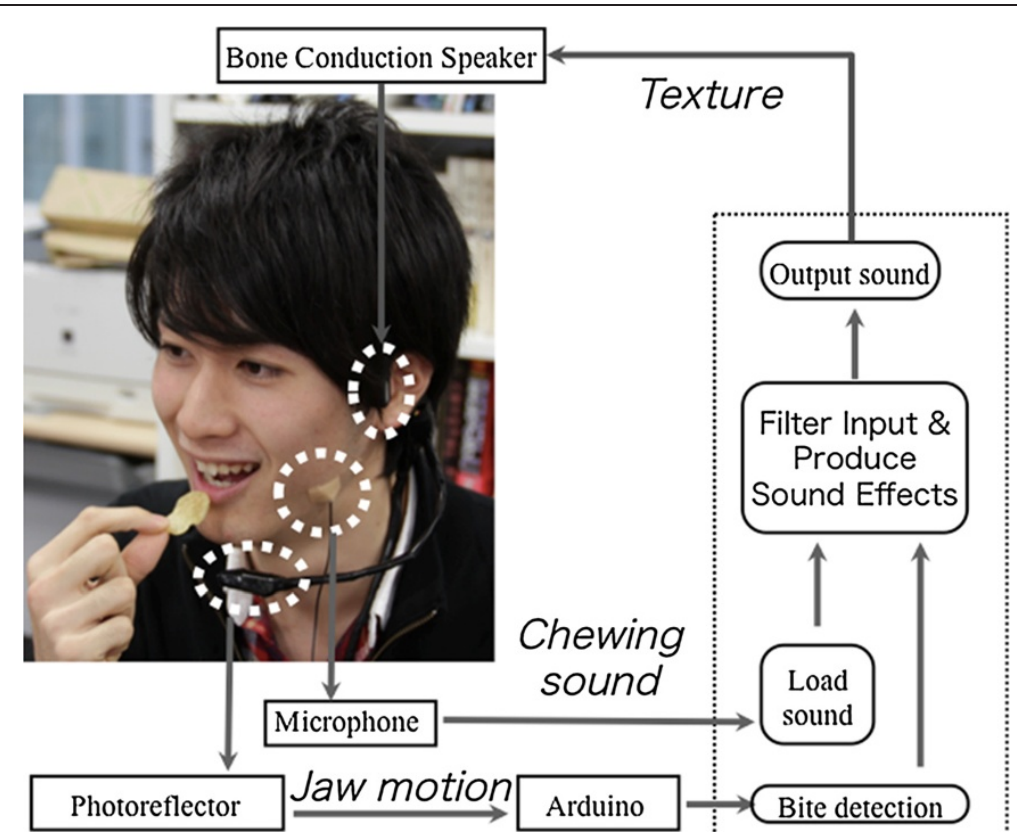

Figure 2 The playful 'Mouth Jockey' detects the user's jaw movements and then plays back a specific pre-recorded sound (Koizumi et al. (2011)).

the tag, and may be surprised to see whatever the designer/chef had in mind. Elsewhere, Naruni and colleagues [37] have used a similar tagging approach in order to develop a multisensory display that, according to the developers at least, could change the perceived flavour of food by means of visual and olfactory AR. The device recognizes the digital tag, and then changes the visual appearance of the food, and, at the same time, adds the appropriate aroma, to the food.

\section{Fostering healthy eating through the incorporation of} technology at the table

Over and above any potential use of digital technology to enhance the experience of food and drink, or to

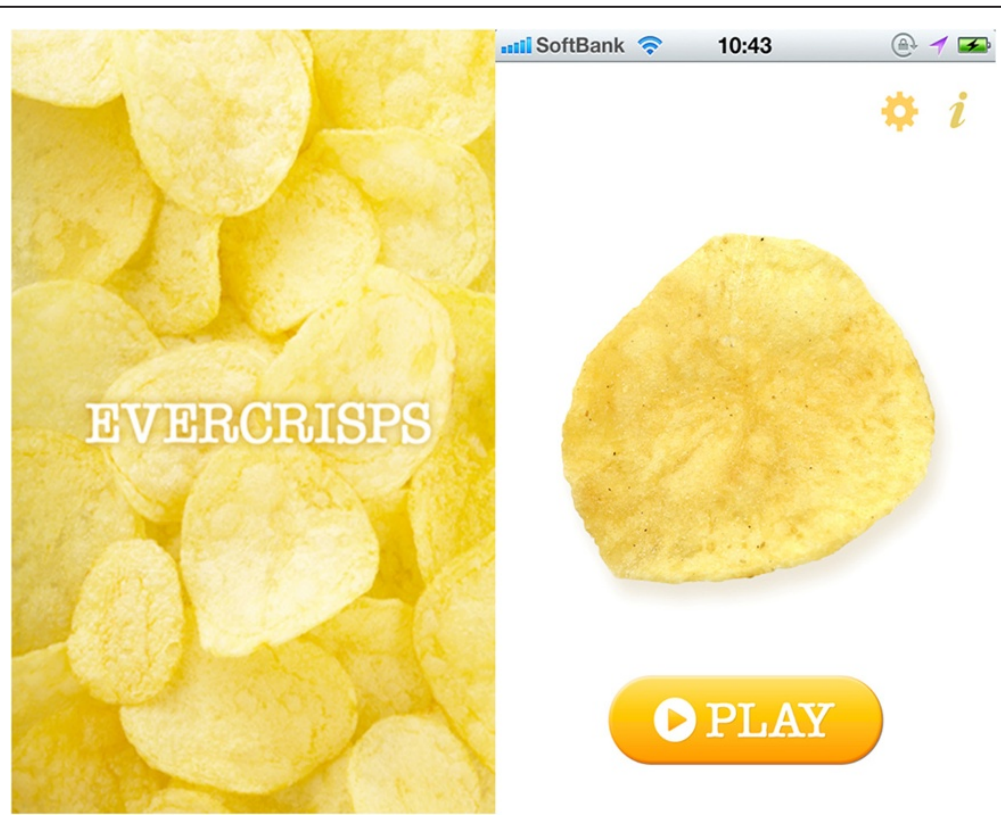

Figure 3 The EverCrisp App., developed by Kayac Inc., Japan, can enhance the crunch of noisy food products by changing the sound that people hear as they bite into a particular food. 


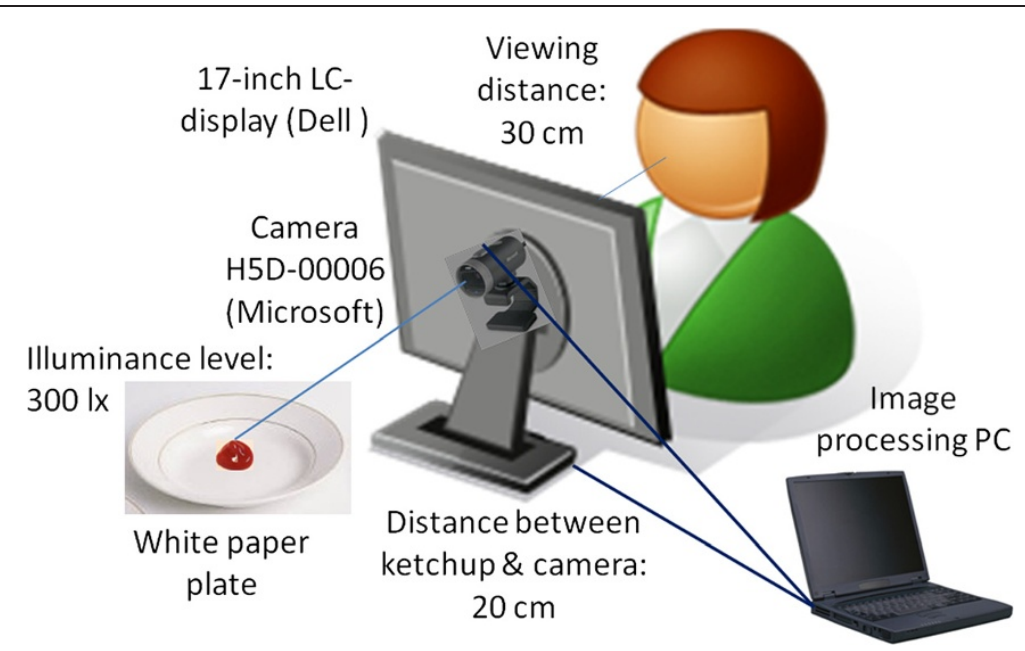

Figure 4 AR and VR developments that enable their users to change the apparent colour, texture, and even the size of the food that they are eating [30].

provide entertainment for the diner, a number of researchers have now started to turn their attention to the question of whether digital technologies can be used to help people control/modify their eating behaviours. There can be no doubt but that the worldwide obesity crisis represents one of the more serious challenges facing society today (for example, see [38]). Given the failure of many traditional (for example, informational) approaches to tackling this crisis, researchers are increasingly considering what alternative strategies can be used to help people to modify their food behaviours [39]. Relevant in this regard, Toet and colleagues [40] have recently been trialling digital cutlery and plateware. So, for example, they have developed a sensor-rich spoon that can vibrate if it (the 'intelligent spoon' that is) detects that the person using it is eating too rapidly. The idea here is that the technology might once again provide a subtle nudge [41] to encourage the overweight, or healthconscious, diner to eat more slowly (and hence, ultimately, hopefully to eat less). The EsTheremine talking fork (or, better said, fork-like instrument), developed recently by Japanese researchers [42] could also be used to deliver health-related messaging to diners. A similar concept is brought by HAPILabs. They have developed the HAPIfork (and spoon) [43,44], which is an eating tool that measures how long you eat for, how long between each mouthful, and how many of them you take. It uses the data to give you feedback on your eating habits which can be viewed online via a web interface (similar to sports-tracking-style websites). There are also a number of mobile Apps, that allow one to track one's eating behaviour on the go (with a 21-day training plan included) to get you on the right path. In addition, this device also vibrates to remind you to slow down, if necessary. So, why think about a personal trainer when your own cutlery can itself potentially help you to eat more healthily? In a project funded by Philips Research, Toet et al. also investigated the feasibility of having people eat from plates that have digital scales embedded in them, in order to calculate the total amount of food that a person has eaten.

Such health and wellbeing related use of technology seems more likely to make its first appearance in the home environment. Who, after all, goes out to eat if they are trying to watch their weight? While such research on the use of digital technology to improve our eating behaviours is still in its infancy, it nevertheless represents a promising, not to mention important, area for future research.

In recent years, Philips Research has also been working on developing a concept that goes by the name of the Diagnostic Kitchen. The idea is to allow users to take an accurate and personally relevant look at what they happen to be eating [45]. Rather than relying on general information, such as the 'recommended daily intake', the idea is that the technology could scan food in order to analyze how well it matches the user's current needs. By using 'the Nutrition monitor', consisting of a scanning 'wand' and swallowable sensor, one would be theoretically able, for example, to determine exactly how much to eat in order to match one's digestive health and nutritional requirements. All of this could obviously be of great benefit for those trying to maintain a healthy diet. In a related vein, Hoonhout et al. [46] have been investigating a number of possibilities (and challenges) associated with the digitization of menu/recipe recommendations, and how digital technology could potentially be used to support our healthy food choices (for example, by providing us with the relevant nutritional information at the most appropriate time). Meanwhile, Noronha and colleagues [47] have developed a crowd-sourcing nutritional analysis system designed to help people change their eating habits. 
One other intriguing AR application here has emerged from research reported by Narumi et al. [48]. These scientists have developed an AR system (based on the food tagging system mentioned earlier) capable of modifying the visually-perceived size of a hand-held food item, not to mention the hand holding that food. The health-related notion here was that people might eat less if it appears as if they are consuming a larger piece of food, than a normal, or miniature-sized food item (see [49] for a review of the literature on size perception and food consumption). The results of preliminary research using this system have been encouraging. In particular, Narumi et al. were able to demonstrate (in one experiment) that people consumed less when the food that they had been given to eat (a large biscuit in this case) was made to look bigger than it actually was.

Technology can also be used to help us enjoy eating more healthily even if we do not find vegetables particularly tasty. Recent research has demonstrated that it is possible to stimulate the taste buds using technology (rather than specific tastants) [50]. They have built a system that delivers and controls the sensation of taste digitally on the human tongue through electrical and thermal stimulation. Basically, the system is capable of giving users the impression that they can perceive certain tastes where there may be none, or else to complement (or mask) certain tastes where there are others.

Of course, in all of the cases just mentioned, the proof will be in the pudding in terms of whether these technologies ultimately prove any more successful than previous attempts to make a significant impact on the impending obesity crisis.

\section{Technology and distraction}

Given the increasing appearance of technology at the tables of a number of the world's cutting-edge restaurants (see the above examples), and thereafter at the home dining table, one perhaps needs to take a step back and consider whether it is necessarily always a good thing (to bring technology to the dining table). While the use of technology in this domain certainly holds the potential to enhance the diner/drinker's experience, or to allow a restaurant to differentiate itself from the opposition in the challenging world of fine dining, it is important to remember that it can also provide an unwanted form of distraction. Indeed, linking back to the question of healthy eating, one worrying finding is that people's food consumption has been shown to increase by as much as $15 \%$ when they are distracted by the radio/TV while eating $[51,52]$. The relevant percentages when it comes to the change in consumption associated with a person being distracted by their mobile device at the dinner table is currently unknown.

'The mist at the Rainforest Café appeals serially to all five senses. It is first apparent as a sound: Sss-sss-zzz.
Then you see the mist rising from the rocks and feel it soft and cool against your skin. Finally, you smell its tropical essence, and you taste (or imagine that you do) its freshness. What you can't be is unaffected by the mist.' ([53], p. 104)

A number of writers (and one suspects many diners) have already commented on the dangers associated with the introduction of technology to the dining table (or dining room): the principle concern here seems to be that the technology (and the multisensory dining experiences that that technology can sometimes facilitate; see, for example, the above quote from [53]) can end up becoming more important than the food/drink itself [54-56]. ${ }^{\mathrm{g}}$ Indeed, there is always going to be a danger that the quality of the food/drink offering will start to suffer whenever the technology takes centre-stage in the dining (or diner's) experience. Ideally, of course, as we have already seen, the technology should help to enhance the dining experience.

In fact, thinking more strategically, it could be argued that such technologies will only stick in the marketplace if they are capable of providing a demonstrable benefit in terms of enhancing the diner's multisensory experience.

\section{Using technology to control the multisensory atmosphere at the dining table}

Another way in which digital technology is increasingly being put in the hands of the diner is illustrated by those restaurants where the diner can actually change the atmosphere (normally the colour of the lighting) in their dining space (see, for example, Pod restaurant in Philadelphia [57]). Interestingly, Philips Research has been working on similar technologies for use in the home environment. The idea here is to enable the home-owner (and hence, potentially, also the home owner's dinner guests) to control the multisensory atmosphere by choosing from a range of pre-selected combinations of ambient lighting, music, not to mention scent, all designed to convey a particular multisensory mood or ambiance [58].

Given such technology, one could, for example, think of adding real value to the experience by marrying the opportunity to control the multisensory atmospherics with research findings showing how the experience might potentially be enhanced. Take, for example, the finding that wine (but presumably also other food and beverage products) tastes sweeter when consumed under red ambient lighting, than under blue, green, or white lighting [59]. Suddenly, the technology conveys a meaningful benefit (over and above any entertainment value that it may have). Here, one could think of using the technology to season the food/drink (for example, potentially making it taste sweeter) without necessarily having to reach for the sugar (and all the associated calories). 
Elsewhere, Gal et al. [60] have reported that the overall level of the ambient lighting impacts on how much people enjoy their coffee. People who like strong coffee tend to drink more of it under brighter ambient illumination conditions, whereas those who like their coffee weaker drink more under more subdued lighting. Lowering the ambient lighting level might also be used to help mask the colours (and hence taste) of any food that happens to be, for whatever reason, visually less-appealing [61]. In summary, the range of scientific insights that are now available concerning the effects of the multisensory atmosphere on the pleasantness and enjoyment of food could be used in the service of digital technology, potentially giving it a purpose in terms of enhancing the diner's experience, rather than just serving to offer the diner an entertaining distraction.

That said, the most pronounced enhancement of the customer's gustatory experiences is likely to occur when they are put in charge not only of the ambient lighting (both its absolute level and hue), but also the music/sounds that they happen to be hearing [21,62-64]. It is to the auditory attributes of the environment that we turn next.

\section{On the neuroscience of matching sound to food (and how technology might help)}

It is not just the visual atmosphere that can be changed in order to enhance the taste/flavour of that which is being consumed. A large body of empirical research now shows the profound effect that what we listen to has on everything from the food and drink choices we make $[65,66]$ through to the experience of the very taste of the food and drink itself $[67,68]$ (see $[21,69]$ for reviews). In the future, it is to be anticipated that we will increasingly see technology being used to allow for the personalized delivery of music and/or soundscapes to individual tables (where, for example, a group of friends may be sharing a bottle of wine, say), or even to an individual diner or drinker. In fact, the last few years have seen something of an explosion of research interest in the matching of music/ soundscapes to specific tastes, flavours, and food textures [67,70-73].

Exciting ideas and opportunities are now also starting to emerge here around the intelligent pairing of music designed to support/complement specific brand experiences (for example, see Le Nez de Courvoisier App downloaded from [74], for one such recent example; see also $[21,73,75]$, for a similar approach of matching the music applied to the taste of Starbucks Via coffee).

\section{On the future of technology at the dining table - digital artefacts}

If such insights regarding the cross-modal matching of music/sound to food and drink were to be delivered by means of musical plateware - that is, cups and plates that made music whenever they were picked up, or rotated, or which change the sound they make as the level in your glass slowly goes down (see, for example, the musical coffee cup [76,77]; see also [78]), who knows what entertaining, and possibly enhanced, eating and drinking experiences might be had. Other ideas here involving the use of digital artefacts, include the use of responsive placemats or beermats that potentially could be used to enable a consumer to select the music they like, and which would hopefully enhance their experience, using an interface that is as naturalistic as possible [79]. Hyperdirectional loudspeakers, capable of directing sound at an individual diner/drinker, may also provide for some intriguing opportunities for the targeted delivery of experiential soundscapes for drinkers/diners. ${ }^{j}$

\section{The SmartPlate}

Working at a more conceptual level, Julian Caraulani, a Romanian designer, and finalist in the 2012 Electrolux Design Lab competition, has recently developed a concept going by the name of the SmartPlate [80]. This is an intelligent piece of plateware that, in theory at least, 'understands' food and transforms it into sound. According to the online description [81], this digital artefact would be capable of completing the circle of senses by which we understand what we eat. The idea is that the plate would connect wirelessly to the user's mobile device. Ideally, it will measure the ingredients, identifying them and then precisely attaching musical notes, harmonies and rhythm to each of them. The user will then be able to listen actively, to compose, and to interact with recipes of sound, sharing the experience in the most intimate way: that is, by means of music. While this design idea is undoubtedly intriguing (and successfully captures the current buzz around the synaesthetic matching of sensations) [82], the practicalities associated with matching tastes/flavours to sound might actually prove somewhat harder to develop than the description cited above might lead one to believe.

\section{Time for a 'Gin \& Sonic'?}

Meanwhile, one of the challenges we are currently working on here at the Crossmodal Research Laboratory in Oxford, and which is a little closer to realization than the SmartPlate, goes by the name of the 'Gin \& Sonic'. Denis Martin, a 2 Michelin-starred chef who runs the restaurant Denis Martin in Vevey, Switzerland [83], uses a balloon and a liquid nitrogen bath to create a gin and tonic the likes of which has never been seen (Figure 5). Gin and tonic is poured into a balloon which is then inflated and tied up. The balloon is then carefully submerged in the bath of liquid nitrogen and turned rapidly until it freezes. Once the skin of the balloon has been peeled off, what one is left with is a perfect hollow white sphere of deep-frozen gin and tonic. While the dish itself 


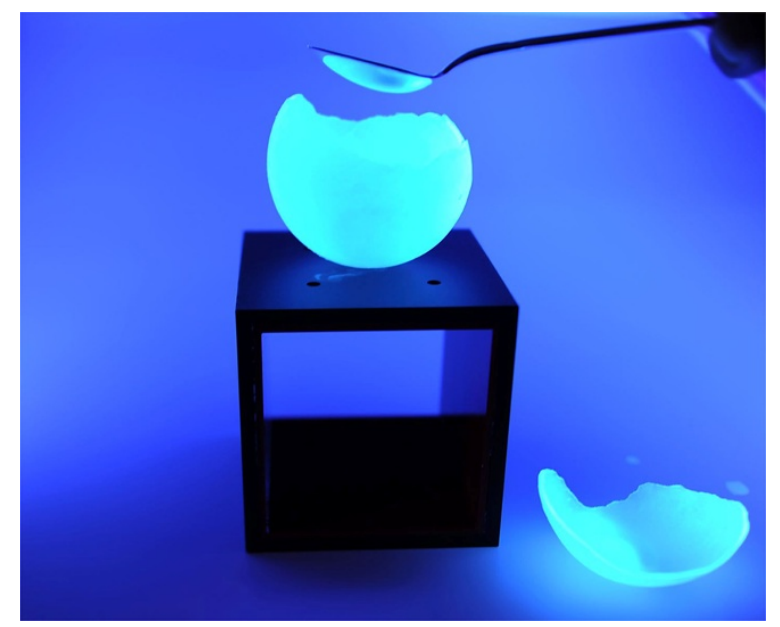

Figure 5 Denis Martin's innovative modernist take on the 'Gin \& Tonic'. Technology can help to bring the sound of carbonation back in a dish that one might then be tempted to call the 'Gin \& Sonic'.

is visually dramatic (not to mention exceedingly tasty), the one thing that is missing from this multisensory experience is the schh....of the tonic gently fizzing in the glass (frozen tonic makes no noise). We are currently collaborating with Condiment Junkie, a London-based sound design/sonic branding agency [84], to embed an actuator (a device that can transform any rigid surface into a loudspeaker) into the plateware in order to bring back the sounds of carbonation, this time through the plateware (see [85], on the importance of sound to the perception of carbonation).

As the above examples have hopefully made clear, digital technology is increasingly being used to help bring sound and food/drink together in a variety of new and creative ways, often embedded in digital artefacts. ${ }^{\mathrm{k}}$ What is particularly exciting, in terms of the future of such crosssensory matching is that experimental dining spaces, such as the workshop of Paco Roncero in Madrid, are now increasingly being fitted out with the technology needed to deliver specific visual, auditory, and increasingly multisensory experiences to diners $[86,87]$. Thus, the technology needed to match the music (or soundscape) to the food exists at a variety of scales. That said, we shouldn't forget what happens at the opposite end of the spectrum. After all, many diners nowadays complain that they cannot hear themselves think in noisy restaurants that seem to have become noisier than ever $[88,89]$. Here, for example, scientists are increasingly thinking about how to harness the latest in technology in order to reduce the din that many of us complain about in restaurants [90].

\section{'The telematic dinner party'}

One problem facing a growing number of us is that we increasingly find ourselves working in a different city (or even country) than our family. As a result, such individuals often miss out on shared family time, time that is typically centred on the dinner table. Barden et al. [4] and Comber and Barden [5] report on the use of technology to allow those who find themselves far apart to share meaningful virtual mealtime/dining experiences. While further research is most certainly needed on this futuristic topic - what has been described as 'the telematic dinner party' (before any workable solution emerges), the findings that have been obtained to date, are nevertheless already still intriguing.

\section{The tablet as 21st century plateware?}

Another of our current favourite ideas around the theme of bringing digital technology to the dining table relates to the possible use of tablet computers as intelligent 21st century plateware (Figure 6). Just think for a moment about how the eating experience could be changed/enhanced if people were to stop being so distracted by their tablets (and other handheld mobile devices) while eating [51] (see [52] on the dangers of distracted dining). Just imagine what possibilities might open up if one were to start serving food from a tablet? ? $^{1}$ One idea that immediately springs to mind here is that it would be possible to change the screen colour (and hence the plate colour) in order to bring out the sweetness in a dish, say. This suggestion is based on recent findings showing that a strawberry dessert is rated as tasting more than $10 \%$ sweeter, and $15 \%$ more flavourful, when eaten from a white plate as compared to when exactly the same food is eaten from a black plate instead $[91,92]$. If matters were that simple though, there would probably be no need for digital plateware at all (just make sure you have a set of white plates). However, it turns out that the optimal plate colour (in term of enhancing the taste/flavour) likely depends on the particular food that is being eaten $[93,94]$. A tablet computer screen would therefore be ideal in terms of being able to generate exactly the right colour background to bring out the taste of the particular dish being consumed from its surface.

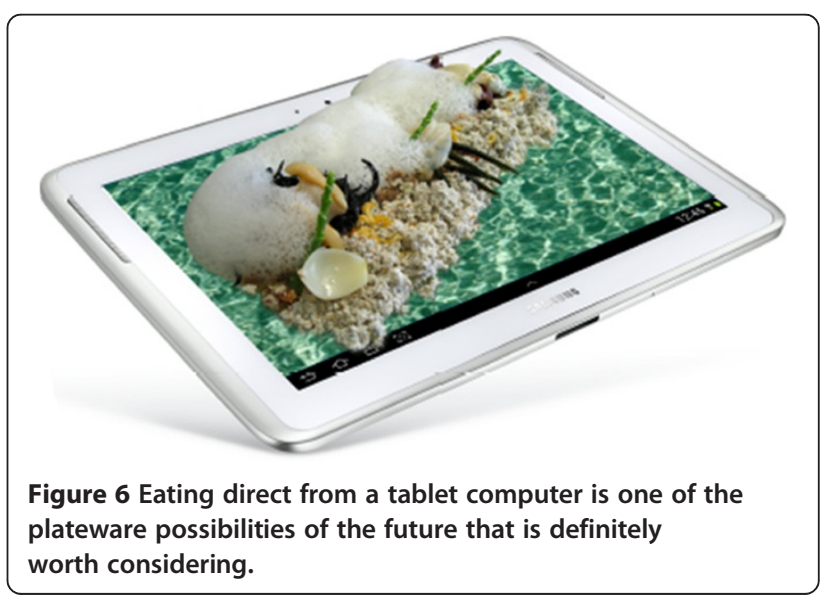


One might also be able to trigger particular kinds of music (or soundscape; see above) depending on what exactly the diner chooses to eat off of the plate at a given time. And, if dining off a tablet should strike you as bizarre, one need only mention the chicken liver parfait currently being served from a brick in one of London's hottest new restaurants (John Salt) for comparison [95]; to see how the envelope is currently being pushed in terms of plateware design [12]!

Talking of which, Philips Design has also been exploring a new range of plateware concepts in its latest design probes. ${ }^{\mathrm{m}}$ They have been exploring how the integration of light, conductive printing, selective fragrance diffusion, micro-vibration and the integration of other sensory stimuli might affect the eating experience [45]. So, for example, in the design probe that goes by the name of 'Multisensorial Gastronomy', researchers have been exploring how the eating experience can be enhanced or altered by stimulating the senses using the integration of electronics, light, and other stimuli (Figure 7). Developed in collaboration with Michelin-starred chef Juan Maria Arzak [96], the four design concepts of interactive tableware - Lunar Eclipse (bowl), Fama (long plate) and Bocado de Luz (serving plate) and the Eye of the Beholder (platter) - react to food placed on the plates or to liquid poured into the bowl.

However, before we close this section, it is important to note that one other important use of digital technology at the dining table, especially at the table of the molecular gastronomy restaurant, will be to help maintain the element of surprise [97] that constitutes such a signature feature of the food served in such venues $[98,99]$.

\section{On the future of technology at the table}

As food and technology increasingly come together at the dining table, two other changes will likely also occur:

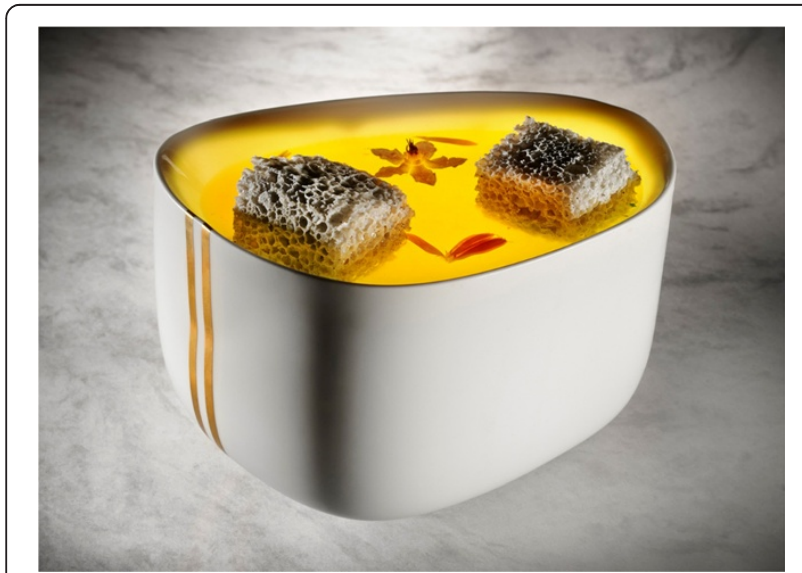

Figure 7 Multisensorial Gastronomy: Philips Design and Arzak present a new generation of multi-sensorial tableware. (Copyright Philips).
1. Restaurant or science laboratory?

We already see signs that the increasing appearance of technology at the front of house may, in some cases at least, start to blur the boundaries between the restaurant dining table and the science laboratory (Figure 8). Indeed, some of the world's top culinary institutes already boast of having dining spaces wired up where those who are eating/drinking can more or less unobtrusively be observed by means of cameras, directional microphones, hidden weights to measure the amount of food that has been served and then consumed, and even 'face readers' to detect/ discriminate their diners'facial expressions (for example, see the Restaurant of the Future, in Wageningen, Holland, [100]; or, the experimental restaurant at the Institut Paul Bocuse, in Lyon, France [101]). Elsewhere, it is now becoming harder to distinguish, some high-end dining spaces from the cutting-edge (albeit exceedingly well-funded) science lab focused on the study of food perception under more or less ecologically-valid testing conditions

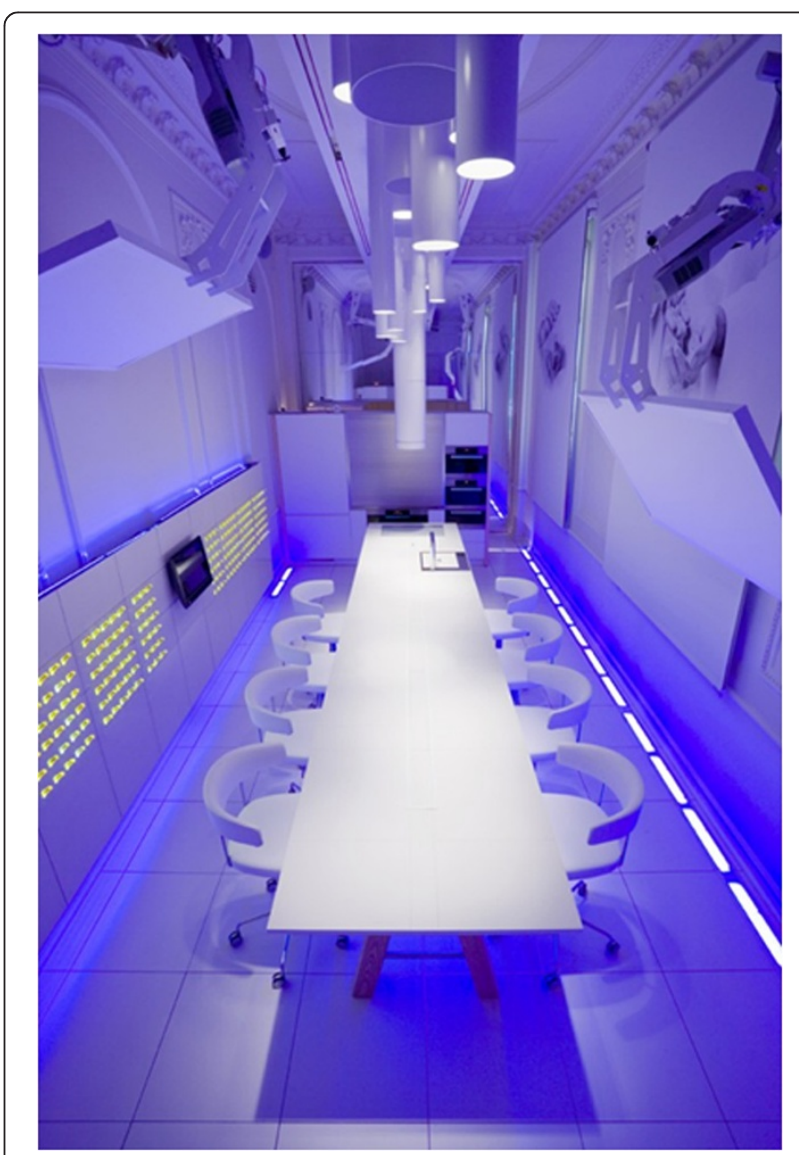

Figure 8 Restaurant or experimental laboratory? The introduction of technology is starting to blur this boundary in some cases. (The workshop of Paco Roncero, Madrid, Spain. Picture reprinted from Jakubik, 2012). 
[86]. One can perhaps see this blurring of the boundaries between restaurant and laboratory as the natural extension of the increasingly scientific research laboratories that have, over the last few years, started to spring up in support of some of the world's top restaurants [102], and René Redzepi's Noma Lab in Copenhagen [103].

'At Grant Achatz's one-of-a-kind restaurant, the chefs are scientists and the kitchen is a laboratory' (taken from an online descriptions of Grant Achatz's Alinea restaurant in Chicago [104]).

2. Culinary art and food art

We also believe that artists/conceptual chefs will, in the coming years, increasingly start to make creative use of the emerging digital technologies when working with food, no matter whether the food is to be eaten or merely viewed [105]. In fact, it will not be any surprise to see more of the intriguing ideas that were first championed by the Italian Futurists [106] appearing on dining tables sometime soon [107]. Indeed, a number of them already have: take, for example, the idea of spraying some or other fragrance over the diner's plate. This idea, first suggested by F. T. Marinetti, ${ }^{\text {n }}$ was recently executed in the oyster dish at The Fat Duck restaurant where the waiter sprays lavender over the dish once it has been placed in front of the diner [2]. In fact, scentdelivery technology is now starting to appear in the experimental workshops, or should that be restaurants, of a number of innovative chefs $[45,86]$.

\section{Conclusions}

In conclusion, it seems clear that technology will increasingly come to change the way in which many of us interact with food and drink in the years to come. Our prediction is that this will start at the tables of the cutting edge (including, but not restricted to molecular gastronomy, or modernist) restaurants, but that a number of the most successful technologies trialled there will, sooner or later, likely make their way onto the home dining table. It is, however, important to bear in mind here that there are at least two distinct routes by which technology will make its way to the dinner table: either it may be supplied by the restaurant or else it may be brought to the table (either in the restaurant or home dining setting) by the diners themselves. Indeed, given the explosion of handheld mobile technologies in recent years [108], it would seem probable that the latter will be the primary route for the mixing of the two. Here it should also be noticed how technology companies such as Philips Research, Electrolux and Microsoft Research are all thinking about the ways in which technology may be introduced to the kitchens of the future $[45,80]$. This, then, might provide an additional route by which technology eventually appears at the dining table.
In conclusion, in this article, we have reviewed a number of the various ways in which digital technology may change the experience of food and drink. To recap, technology may be used to facilitate our interaction with (knowledge about) that which we are eating and drinking, by enhancing the entertainment value, by providing targeted multisensory interventions to diners, by providing nudges to those who may wish to eat more healthily. On the flip side, the biggest danger that we see currently is that the technology becomes nothing more than a distraction for the diner (and possibly results in an unwanted, and likely unnoticed, increase in food intake). However, in the best case scenario, we believe the potential benefits of bringing technology to the dining table hold the potential to transform many of our dining experiences in a manner similar to the way that the introduction of new technology/techniques at the back of house helped to usher in the era of molecular gastronomy, especially if the technology is linked with the relevant behavioural science the benefits are likely to outweigh the costs.

\section{Consent}

Written informed consent was obtained from the person for publication of this report and any accompanying images.

\section{Endnotes}

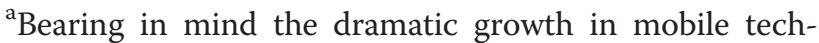
nologies, twinned with the profound development of computational power increasingly found in such devices [108], it is likely that the most prevalent, not to mention sophisticated technology at the table will soon mostly be embedded in such handheld devices.

${ }^{b}$ According to their website: 'At the core of Inamo is our interactive ordering system. .... You'll set the mood, discover the local neighbourhood, and even order a taxi home.'

'Spence et al. [19] conducted research in Oxford that demonstrated that people rate seafood as tasting significantly better when listening to a soundtrack like the sound of the sea, than when listening to another (incongruent) soundtrack.

${ }^{\mathrm{d}}$ Note also that molecular mixologists are increasingly following ever closer on the heels of the molecular gastronomists [109-111].

${ }^{\mathrm{e}}$ Many of these applications have also garnered more than their fair share of media coverage [112,113].

fZampini and Spence [28] conducted research demonstrating that people's perception of the crunchiness/ freshness of potato chips could be increased by as much as $15 \%$ simply by modifying the self-generated sounds that people hear when biting into food. This research was awarded the 2008 IG Nobel Prize for Nutrition! 
${ }^{\mathrm{g}}$ Though note that such concerns do not seem to have been voiced when it comes to The Tonga Room \& Hurricane Bar which opened at the Fairmont Hotel, in San Francisco back in 1945 [114,115].

${ }^{h}$ Note that this effect was observed despite the fact that the wine itself was served from black tasting glasses to ensure that the colour of the drink did not change when the ambient lighting was manipulated. The effect of changing the ambient illumination might be expected to have an even bigger effect on people's taste/flavour perception should the apparent colour of the food/drink also change.

${ }^{\mathrm{i}}$ Note that digital technology (especially computers) will increasingly appear in digital artifacts, such as the Mediacup where the computer becomes increasingly invisible to the diner, who will increasingly find him-/herself interacting with the technology implicitly [78].

${ }^{j}$ Note here that headphones, while obviously allowing for the targeted delivery of sound, provide a less than optimal means of delivering sound in social situations.

${ }^{k}$ Elsewhere, an Italian company has recently developed a line of musical beer bottles [116].

${ }^{1}$ Acknowledging, of course, the difficulty of keeping such technology clean.

${ }^{\mathrm{m}}{ }^{\prime}$ The FOOD design probe: A far-flung design concept; A provocative and unconventional look at areas that could have a profound effect on the way we eat and source our food 15-20 years from now.' (taken from The Philips design website [45]).

${ }^{n}$ In the cucina futuristica: 'Meals were to be eaten to the accompaniment of perfumes...to be sprayed over the diners, who, fork in the right hand, would stroke meanwhile with the left some suitable substance - velvet, silk, or emery paper.' (for example, see [117], p. 61). Such ideas (well, at least the idea of spraying a fragrance over a dish in front of the diner) can nowadays be seen echoed in a number of contemporary molecular gastronomy dishes.

\section{Competing interests}

The authors declare that they have no competing interests.

\section{Authors' contributions}

Both authors contributed to the writing of this article, and read and approved the final manuscript.

Received: 14 January 2013 Accepted: 7 February 2013

Published: 11 March 2013

\section{References}

1. Miller G: The smartphone psychology manifesto. Perspect Psychol Sci 2012, 7:221-237.

2. Blumenthal $\mathrm{H}$ : The big Fat Duck cookbook. London: Bloomsbury; 2008.

3. Myhrvold N, Young C: Modernist cuisine. The art and science of cooking. La Vergne, TN: Ingram Publisher Services; 2011.

4. Barden P, Comber R, Green D, Jackson D, Ladha C, Bartindale T, Bryan-Kinns N, Stockman T, Olivier P: Telematic dinner party: Designing for togetherness through play and performance. In Proceedings of the ACM
Conference on Designing Interactive Systems 2012 (DIS2012). New York, NY: ACM; 2012:38-47.

5. Comber R, Barden P: Not sharing sushi: Exploring social presence and connectedness at the telematic dinner party. In To appear in Eat, cook, grow: Mixing human-computer interactions with human-food interactions. Edited by Choi JH-J, Foth M, Hearn G. Cambridge, MA: MIT Press; in press.

6. Vega C, Ubbink J, van der Linden E: The kitchen as laboratory: Reflections on the science of food and cooking. New York, NY: Columbia University Press; 2012.

7. Schira R: Daniel Facen, the scientific chef. 2011. http://www.finedininglovers. com/stories/molecular-cuisine-science-kitchen/.

8. O'Hara K, Helmes J, Sellen A, Harper R, ten Bhömer M, van den Hoven E: Food for talk: Phototalk in the context of sharing a meal. HumanComputer Interaction 2012, 27(1-2):124-150.

9. "Food photos: How to do it properly": BBC News Magazine. 2013. http:// www.bbc.co.uk/news/magazine-21235195

10. Inamo Restaurant. http://www.inamo-restaurant.com/pc/.

11. Swaroop Dash S: With Moneual Smart Table You Order And Pay For Food; Yes You Even Eat On It Too!. http://www.crazyengineers.com/with-moneualsmart-table-you-order-and-pay-for-food-yes-you-even-eat-on-it-too/.

12. John Salt - Spectacular Culinary Experience. http://londontastin.com/post/ 36500907797/john-salt-spectacular-culinary-experience.

13. Turnball T: The 50 top food websites. The Times, January 30; 2013:1-4. http:// www.thetimes.co.uk/tto/life/food/article3671812.ece.

14. Choi JHJ, Foth M, Hearn G: Mixing human-computer interactions with human-food interactions. Cambridge, MA: MIT Press; in press.

15. El Celler de Can Roca.; . http://vimeopro.com/user10658925/el-celler-de-canroca/video/40919096.

16. I-Bar. http://www.i-bar.ch/.

17. The Fat Duck; http://www.thefatduck.co.uk/.

18. Schöning J, Rogers Y, Krüger A: Digitally enhanced food. Pervasive Computing 2012, 11:4-6.

19. Spence C, Shankar MU, Blumenthal H: 'Sound bites': Auditory contributions to the perception and consumption of food and drink. In Art and the senses. Edited by Bacci F, Melcher D. Oxford: Oxford University Press; 2011:207-238.

20. De Lange C: Feast for the senses: Cook up a master dish. New Scientist, 2896 (18th December 2012). http://www.newscientist.com/article/ mg21628962.200-feast-for-the-senses-cook-up-a-master-dish.html.

21. Spence C: Auditory contributions to flavour perception and feeding behaviour. Physiology \& Behaviour 2012, 107:505-515.

22. Grimes A, Harper R: Celebratory technology: New directions for food research in $\mathrm{HCl}$. In Proceedings of the Twenty-Sixth Annual SIGHCI Conference on Human Factors in Computing Systems (CHI'08). Florence; 2008:467-476.

23. Gastro Tech Days; http://www.gastrotechdays.com/.

24. Hashimoto $Y$, Inami M, Kajimoto H: Straw-like user interface (II): A new method of presenting auditory sensations for a more natural experience. In Eurohaptics 2008, LNCS, 5024. Edited by Ferre M. Berlin: Springer-Verlag; 2008:484-493.

25. Hashimoto Y, Nagaya N, Kojima M, Miyajima S, Ohtaki J, Yamamoto A, Mitani T, Inami M: Straw-like user interface: Virtual experience of the sensation of drinking using a straw. In Proceedings World Haptics 2007. Los Alamitos, CA: IEEE Computer Society; 2007:557-558.

26. Wei J, Nakatsu R: Leisure food: derive social and cultural entertainment through physical interaction with food. Entertainment Computing-ICEC 2012, 2012:256-269.

27. Koizumi N, Tanaka H, Uema Y, Inami N: Chewing jockey: Augmented food texture by using sound based on the cross-modal effect. In Proceedings of ACE'11, Proceedings of the 8th International Conference on Advances in Computer Entertainment Technology, Article No. 21. New York, NY: ACM; 2011.

28. Zampini M, Spence C: The role of auditory cues in modulating the perceived crispness and staleness of potato chips. J Sensory Sci 2004, 19:347-363.

29. Narumi T, Kajinami T, Tanikawa T, Hirose M: Meta cookie. ACM SIGGRAPH 2010 Emerging Technologies Article No. 18. New York, NY: ACM; 2010.

30. Okajima K, Spence C: Effects of visual food texture on taste perception. Perception 2011, 2. http://i-perception.perceptionweb.com/journal///article/ic966.

31. Sakai N: Tasting with eyes. Perception 2011, 2. http://i-perception. perceptionweb.com/journal///article/ic945.

32. Augmented reality cookies; [http://www.youtube.com/watch? $\mathrm{v}=\mathrm{cbsKSPdOSX0];} \mathrm{[http://www.newlaunches.com/archives/}$ one_cookie_seven_flavors_with_meta_cookie_ar_headgear.php]. 
33. $Q R$ code cookies create unique personalized messages. http://www.springwise. com/food_beverage/qr-code-cookies-create-unique-personalized-messages/. 34. Qkies. http://qkies.de.

35. Augmented Reality Cookies - ARCookies Christmas 2008. http://goo.gl/qXGJF.

36. QKies - sag's mit Keksen. http://www.universalsubtitles.org/de/videos/ S740Qdh7wLI1/info/qkies-sags-mit-keksen/.

37. Narumi T, Nishizaka S, Kajinami T, Tanikawa T, Hirose M: Augmented reality flavors: Gustatory display based on edible marker and crossmodal interaction. In Proceedings of the 2011 Annual Conference on Human Factors in Computing Systems (CHI'11); 2011:93-102.

38. World Health Organization: Obesity: Preventing and managing the global epidemic. Geneva: World Health Organization; 1998.

39. Marteau TM, Hollands GJ, Fletcher PC: Changing human behaviour to prevent disease: The importance of targeting automatic processes. Science 2012, 337:1492-1495.

40. Toet E, Meerbeek B, Hoonhout J: Supporting mindful eating: InBalance chopping board. In To appear in Eat, Cook, Grow: Mixing Human-Computer Interactions with Human-Food Interactions. Edited by Choi JH-J, Foth M, Hearn G. Cambridge, MA: MIT Press; in press.

41. Thaler RH, Sunstein CR: Nudge: Improving decisions about health, wealth and happiness. London: Penguin; 2008

42. Kadomura A, Nakamori R, Tsukada K, Siio I: EaTheremin. In SIGGRAPH Asia 2011 Emerging Technologies:: ACM; 2011:7.

43. Hapilabs. http://www.hapilabs.com/.

44. MacRae F, Prigg M: The fork that could help you lose weight. Daily Mail, 11 January, 2013.

45. Philips Design Futures. http://www.design.philips.com/philips/sites/ philipsdesign/about/design/designportfolio/design_futures/food.page.

46. Hoonhout J, Gros N, Geleijnse G, Nachtigall P, van Halteren A: What are we going to eat today? Food recommendations made easy, and healthy. In To appear in Eat, cook, grow: Mixing human-computer interactions with human-food interactions. Edited by Choi JH-J, Foth M, Hearn G. Cambridge, MA: MIT Press; in press.

47. Noronha J, Hysen E, Zhang H, Gajos KZ: Platemate: Crowdsourcing nutritional analysis from food photographs. In Proceedings of the 24th Annual ACM symposium on User interface software and technology (UIST'11). Santa Barbara, CA; 2011:1-12.

48. Narumi T, Ban Y, Kajinami T, Tanikawa T, Hirose M: Augmented perception of satiety: Controlling food consumption by changing apparent size of food with augmented reality. In Proceedings 2012 ACM Annual Conference Human Factors in Computing Systems; CHI 2012: 5-10 May, 2012. Austin, TX:; 2012.

49. Spence C, Harrar V, Piqueras-Fiszman B: Assessing the impact of the tableware and other contextual variables on multisensory flavour perception. Flavour 2012, 1:7

50. Ranasinghe N, Cheok AD, Fernando ONN, Nii H, Gopalakrishnakone P: Digital taste: electronic stimulation of taste sensations. Ambient Intelligence: Lecture Notes in Computer Science 2011, 7040:345-349.

51. Bellisle F, Dalix AM: Cognitive restraint can be offset by distraction, leading to increased meal intake in women. Am J Clin Nutr 2001, 74:197-200.

52. Wansink $B$ : Changing eating habits on the home front: Lost lessons from World War II research. J Public Policy Marketing 2002, 21:90-99.

53. Pine BJ II, Gilmore JH: Welcome to the experience economy. Harv Bus Rev 1998, 76:97-105

54. Gill AA: Table talk: Sweet and sour, salt and bitter. London: Weidenfeld \& Nicolson; 2007.

55. Goldstein D: The play's the thing: Dining out in the new Russia. In The taste culture reader: Experiencing food and drink. Edited by Korsmeyer C. Oxford: Berg; 2005:359-371

56. Spence C, Piqueras-Fiszman B: Dining in the dark. The Psychologist 2012, 25:888-891.

57. Pod Restaurant. http://www.podrestaurant.com

58. Pelgrim PH, Hoonhout HCM, Lashina TA, Engel J, ljsselsteijn WA, de Kort YAW: Creating atmospheres: The effects of ambient scent and coloured lighting on environmental assessment. Gothenburg, Sweden: Paper presented at the Design \& Emotion conference; 2006.

59. Oberfeld $\mathrm{D}$, Hecht $H$, Allendorf $U$, Wickelmaier F: Ambient lighting modifies the flavor of wine. J Sensory Stud 2009, 24:797-832.

60. Gal D, Wheeler SC, Shiv B: Cross-modal influences on gustatory perception. http://ssrn.com/abstract=1030197.

61. Wheatley J: Putting colour into marketing. Marketing 1973, 24-29:67.
62. Spence $\mathrm{C}$ : The $\mathrm{ICI}$ report on the secret of the senses. London: The Communication Group; 2002

63. Spence C: On crossmodal correspondences and the future of synaesthetic marketing: Matching music and soundscapes to tastes, flavours, and fragrance. In Proceedings of ABA. Oxford:; 2012. in press.

64. Wansink B, Van Ittersum K: Fast food restaurant lighting and music can reduce calorie intake and increase satisfaction. Psychological Reports: Human Resources \& Marketing 2012, 111:1-5.

65. Areni CS, Kim D: The influence of background music on shopping behavior: Classical versus top-forty music in a wine store. Adv Consum Res 1993, 20:336-340.

66. North AC, Hargreaves DJ, McKendrick J: In-store music affects product choice. Nature 1997, 390:132.

67. Crisinel A-S, Cosser S, King S, Jones R, Petrie J, Spence C: A bittersweet symphony: Systematically modulating the taste of food by changing the sonic properties of the soundtrack playing in the background. Food Qual Prefer 2012, 24:201-204.

68. North AC: The effect of background music on the taste of wine. $\mathrm{Br} J$ Psychol 2012, 103:293-301.

69. Spence C, Shankar MU: The influence of auditory cues on the perception of, and responses to, food and drink. J Sensory Stud 2010, 25:406-430.

70. Knöferle KM, Spence C: Crossmodal correspondences between sounds and tastes. Psychon Bull Rev 2012, 19:992-1006.

71. Mesz B, Sigman M, Trevisan MA: A composition algorithm based on crossmodal taste-music correspondences. Front Hum Neurosci 2012, 6:1-6.

72. Spence C: Sound design: How understanding the brain of the consumer can enhance auditory and multisensory product/brand development. In Audio Branding Congress Proceedings 2010. Edited by Bronner K, Hirt R, Ringe C. Baden-Baden, Germany: Nomos Verlag; 2011a:35-49.

73. Spence C: Wine and music. The World of Fine Wine 2011, 31:96-104.

74. Le Nez de Courvoisier App. http://courvoisier.com/uk/le-nez-de-courvoisier-app.

75. Crisinel A-S, Jacquier C, Deroy O, Spence C: Composing with cross-modal correspondences: Music and smells in concert. Chemosens Perception, 6:45-52, doi:10.1007/s12078-012-9138-4.

76. Coffee Music Player. http://www.youtube.com/watch?v=MY3NcckUffM.

77. Interaction Lab. http://interactionlab.kr/Project-Contents_1-5.html.

78. Beigl M, Gellersen H-W, Schmidt A: MediaCups: Experience with design and use of computer-augmented everyday artefacts, Computer Networks. Special Issue on Pervasive Computing.: Elsevier; 1999. http://docis.info/docis/lib/goti/ rclis/dbl/connet/(2001)35\%253A4\%253C401\%253AMEWDAU\%253E/www. comp.lancs.ac.uk\%252F hwg\%252Fpubl\%252Fmediacups.pdf.

79. Butz A, Schmitz M: Design and application of a beer mat for pub interaction http://www.medien.ifi.lmu.de/pubdb/publications/pub/butz2005ubicomp/ butz2005ubicomp.pdf.

80. Electrolux Design Lab. http://www.electrolux.co.uk/Global-pages/ Promotional-pages/Electrolux-Design-Lab/Electrolux-Design-Lab-FinalistsPresent-Concepts-that-Stimulate-the-Senses.

81. Musical Dinner. http://www.yankodesign.com/2012/09/27/musical-dinner

82. Spence C: Synaesthetic marketing: cross sensory selling that exploits unusual neural cues is finally coming of age. The Wired World in 2013, 2012:104-107.

83. Denis Martin Restaurant. http://www.denismartin.ch.

84. Condiment Junkie. http://www.condimentjunkie.co.uk/.

85. Zampini M, Spence C: Modifying the multisensory perception of a carbonated beverage using auditory cues. Food Qual Prefer 2005, 16:632-641.

86. Jakubik A: The workshop of Paco Roncero. Trendland: Fashion Blog \& Trend Magazine; 23/07/2012. http://trendland.com/the-workshop-of-paco-roncero/.

87. Estudio Baselga. http://www.estudiocbaselga.co.uk/estudio/news.

88. Pass the Salt... and a Megaphone. http://online.wsj.com/article/ SB10001424052748704022804575041060813407740.html.

89. No appetite for noise. http://www.washingtonpost.com/wp-dyn/content/ article/2008/04/01/AR2008040102210_pf.html.

90. Clynes T: A restaurant with adjustable acoustics. http://www.popsci.com/ technology/article/2012-08/restaurant-adjustable-acoustics.

91. Piqueras-Fiszman B, Alcaide J, Roura E, Spence C: Is it the plate or is it the food? Assessing the influence of the color (black or white) and shape of the plate on the perception of the food placed on it. Food Qual Prefer 2012, 24:205-208.

92. Piqueras-Fiszman B, Giboreau A, Spence C: Assessing the influence of the colour/finish of the plate on the perception of the food in a test in a restaurant setting. Appetite, submitted. 
93. Harrar V, Piqueras-Fiszman B, Spence C: There's no taste in a white bowl. Perception 2011, 40:880-892.

94. Lyman B: A psychology of food, more than a matter of taste. New York, NY: Avi, van Nostrand Reinhold; 1989.

95. John Salt. http://john-salt.com/.

96. Arzak. http://www.arzak.info/arz_web.php?idioma=En

97. Fellett M: Smart headset gives food a voice. New Scientist; http://www. newscientist.com/blogs/nstv/2011/12/smart-headset-gives-food-a-voice.html.

98. Holler Mielby L, Bom Frøst M: Expectations and surprise in a molecular gastronomic meal. Food Qual Prefer 2010, 21:213-224.

99. Piqueras-Fiszman B, Spence C: Sensory Incongruity: Art, science \& commercialization. Petits Propos Culinaires 2012, 95:74-116.

100. Restaurant of the Future. http://www.restaurantvandetoekomst.wur.nl/UK.

101. Institute Paul Bocuse. http://www.institutpaulbocuse.com/us/food-hospitality/.

102. Ulla G: The future of food: Ten cutting-edge restaurant test kitchens around the world; http://eater.com/archives/2012/07/11/ten-restaurant-test-kitchens.php.

103. First look at Noma's food lab. http://uk.phaidon.com/agenda/design/picturegalleries/2012/march/28/first-look-at-nomas-food-lab/.

104. Grant Achatz \& Secrets of Alinea. http://www.youtube.com/watch? $v=P 7 t 0 E P G K p d M$.

105. Jones CA: Sensorium: Embodied experience, technology, and contemporary art. Cambridge, MA: MIT Press; 2006.

106. Marinetti FT: The futurist cookbook (Trans. S. Brill). San Francisco, CA: Bedford Arts; 1930/1989.

107. Spence C, Hobkinson C, Gallace A, Piqueras Fiszman B: A touch of gastronomy. Flavour, 2. in press. 10.1186/2044-7248-2-14

108. Smartphone Futures 2012-2016; http://www.portioresearch.com/en/reports/ current-portfolio/smartphone-futures-2012-2016.aspx.

109. Sherman L: Molecular mixology; http://www.forbes.com/2008/07/01/ molecular-mixology-cocktails-forbeslife-drink08-cx_Is_0701science.htm

110. Molecular mixology. http://en.wikipedia.org/wiki/Molecular_mixology.

111. The science of drinking at 69 Colebrooke Row. http://www.thecocktaillovers. com/tag/professor-charles-spence/.

112. Fellet M: Smart headset gives food a voice; http://www.newscientist.com/ blogs/nstv/2011/12/smart-headset-gives-food-a-voice.html.

113. Winter K: The fork that talks! New Japanese gadget makes bizarre sounds while you eat. Daily Mail Online; 2012. http://www.dailymail.co.uk/femail/ article-2254192/The-fork-talks-New-Japanese-gadget-makes-bizarre-soundseat.html.

114. Lanza J: Elevator music: A surreal history of Muzak, easy-listening, and other moodsong. Ann Arbor, Ml: University of Michigan Press; 2004.

115. Tonga room. http://en.wikipedia.org/wiki/Tonga_Room.

116. Elav Brewery. http://www.elavbrewery.com/it/birre-elav.

117. David E: Italian food. 3rd edition. London: Penguin; 1987.

doi:10.1186/2044-7248-2-16

Cite this article as: Spence and Piqueras-Fiszman: Technology at the

dining table. Flavour 2013 2:16.

\section{Submit your next manuscript to BioMed Central and take full advantage of:}

- Convenient online submission

- Thorough peer review

- No space constraints or color figure charges

- Immediate publication on acceptance

- Inclusion in PubMed, CAS, Scopus and Google Scholar

- Research which is freely available for redistribution

Submit your manuscript at www.biomedcentral.com/submit 